\title{
Framing rhino horn demand reduction in Vietnam \\ Dismissing medical use as voodoo
}

\begin{abstract}
According to Milliken and Shaw (2012) a surge in illegal rhino poaching in South Africa since 2006 was linked to increasing demand for rhino horn in Vietnam. This article examines one of the key frames, the 'Voodoo Wildlife Parts' (VWP) frame, which Environmental Non-Government Organisations (ENGOs) in Vietnam have been using in rhino horn demand reduction media campaigns. The VWP frame emerged from the findings of a research project that investigated the news frames present in the media outputs of seven ENGOs, both local and international, opposing the Illegal Wildlife Trade (IWT) in Vietnam. This article will briefly outline the four frames that emerged from that research, then discuss the two subthemes of the VWP frame and its scientific basis and the nature of the feedback from journalists and the public that influenced the frame's production.
\end{abstract}

Keywords: environmental non-government organisations (ENGOs), framing, illegal wildlife trade (IWT), news framing, rhino, rhino horn, South Africa, Vietnam, wildlife trafficking

\section{MICHAEL SCOTT SMITH \\ Griffith University, Queensland}

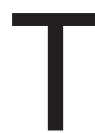

HE ILLEGAL Wildlife Trade is considered the world's biggest threat to many species (Truong, Dang, \& Hall, 2016). Environmental NGOs have been working to combat a resurgence in the poaching of rhinos for their horns in Africa and other rhino range states for the past 10 years. The poaching is directly linked to demand in Vietnam (Rademeyer, 2012), where rhino horn is widely purchased and used (Truong, et al., 2016). Milliken (2014) reported that the illegal supply of rhino horn from Africa to Asia increased by 30 -fold from 2000 to 2013.

Critically endangered Black Rhino are listed in Convention on International Trade of Endangered Species of Wild Fauna and Flora (CITES) Appendix 1 (Emslie, 2012a), while near threatened White Rhino in South Africa are listed 
in Appendix 1 and 2 (Emslie, 2012b). Efforts by ENGOs in South Africa to directly reduce the poaching have been coupled with communication efforts in Vietnam and China, which are the main markets for rhino horn, to strengthen enforcement and change consumer behaviour to reduce demand. ENGOs, government stakeholders and international donors attended a high-level international conference to tackle IWT in Hanoi in Vietnam in November, 2016. ENGOs at the conference discussed various communication strategies they were developing to reduce demand for rhino horn and other priority IWT products.

This article outlines findings of a project that researched the media outputs of ENGOs working in Vietnam to reduce demand for rhino horn, by identifying and analysing the news frames present in their press releases (Smith, 2017). As news framing concerns the construction and interpretation of meaning (Gitlin, 1980; Entman, 1993), the framing analysis of the ENGO press releases provided valuable insights into the ENGOs' media strategies. The frames that emerged from the analysis were: Voodoo Wildlife Parts, Responsibility, Empower and Lip Service. This study focuses on Voodoo Wildlife Parts, perhaps the most widely mediatised and most contentious of the four frames.

\section{Table 1: Dominant and competing press release key frames, 2017}

\begin{tabular}{|l|c|c|c|}
\hline Frame & Dominant & Competing & Total \\
\hline Responsibility & 22 & 30 & 52 \\
\hline Lip Service & 22 & 15 & 37 \\
\hline Empower & 14 & 30 & 44 \\
\hline Voodoo Wildlife Parts & 14 & 32 & 46 \\
\hline
\end{tabular}

Source: Table showing the total of dominant and competing ENGO key frames in the Vietnam press release sample (see Smith, 2017)

The name Voodoo Wildlife Parts was derived by an evocative in vivo term (Given, 2008) coined by an ENGO personnel during an interview. The VWP frame concerned the medical and emotional use of rhino horn from a scientific and Traditional Medicine (TM) aspect. Although rhino horn has been shown to have some medical efficacy to treat fever and has been used by TM practitioners for millennia, the increasing demand for rhino horn in Vietnam was fuelled by rumours of unscientifically proven medical benefits such as a body detoxifier and a cure for conditions from hangovers to cancer to a potion for success.

By drawing on interdisciplinary literature on ENGOs, IWT, environmental communication and news framing, this article aims to fill a gap in the framing research regarding the specific area of IWT. It aims to complement recent studies into rhino horn consumer behaviour and demand (Truong, et al., 2016; Drury, 2009; Burgess, 2016) by using framing theory to analyse the strategies used by ENGOs. Hansen (2011) argued that framing studies provided productive frameworks to analyse environmental communication, but noted that there were 
few studies into the careers of environmental claims makers. There is a growing NGO lobby in Vietnam (Smith, 2008), while ENGOs are responsible for new ways of talking about the environment in China (Yang \& Calhoun, 2013) and Vietnam (Cooper, 2006; Mol, 2009). A better understanding of the media work that these ENGOs are doing is critical, as rhino poaching figures in Africa have increased (Milliken \& Shaw, 2012). This article also aims to suggest ways the VWP frames and the processes can be improved to assist ENGOs to be more effective in their communications to reduce demand and contribute to saving a threatened species.

\section{Methodology}

The research project this study is drawn from (Smith, 2017) used a mixed method approach to firstly identify key frames used to reduce demand for rhino horn in Vietnam, secondly to discover the cultural and other factors that influenced the production of the frames and thirdly to investigate the efficacy of the frames and strategies used by the ENGOs to achieve their goals.

The ENGOs selected for the study came from a small pool of ENGOs working in the IWT area and were selected on three main criteria:

- They were prominent.

- They had an office or a partner with an office in Vietnam.

- They produced press releases that were archived on their website regarding the illegal rhino horn trade in Vietnam.

The ENGOs that produce media outputs to reduce demand for rhino horn in Vietnam were all present at the Hanoi Conference on IWT on 17-18 November 2016. Seven of the nine ENGOs at the conference doing work on the rhino trade were included in the study, including a mix of international and local ENGOs. These were local ENGOs: Education for Nature Vietnam (ENV), WildAct and Change, and international ENGOs (IENGOs): Wildlife Conservation Society (WCS), Trade Records Analysis of Flora and Fauna in Commerce (TRAFFIC), World Wildlife Fund (WWF) and WildAid. To identify the framing that the ENGOs used, the study used press releases and interviews with key personnel.

A total of 76 English language press releases from between 2014 and 2016 were selected from the websites of the ENGOs. A traditional analogue approach using printed out press releases and different coloured highlighters was used in the analysis. To identify the four key frames, framing theory (Gamson \& Modigliani, 1989; Tankard, 2001; Cappella \& Jamieson, 1997) and a framing analysis methodology adopted by Blood, Putnis \& Pirkis (2002, p. 59) were employed. Frames were identified through persistent inclusion, exclusion and emphasis (Gitlin, 1980); placement of information, its prominence, repetition or association with culturally familiar language and symbols (Entman, 1993, p. 53; Phalen \& Algan, 2001, p. 303; and images (Gamson \& Modigliani, 1989). 
Entman's (1993) four functions of frames: 'problem definition, causal interpretation, moral evaluation and/or treatment recommendation' and Benford and Snow's (2000) motivational tasks for social movements were used to further clarify the nature of the frames

To explore the factors that influenced the framing, the methodology drew on a combination of internal and external approaches (Anderson, 1997, p. 34) used by Lowe and Goyder (1983) in a seminal study of environmental groups in Britain. A social constructionist perspective (Blumer, 1971; Schneider, 1985; Spector \& Kitsuse, 1973, as cited in Hansen, 2011, p. 9) that views how knowledge and meaning is created by the subjects' interactions was taken. At the conference I conducted semi-structured interviews with key ENGO personnel involved in the production of media outputs. Recordings of four key TRAFFIC personnel, presenting at the 'Behaviour change to combat wildlife crime' seminar at the conference, were also included in the data. The interviews were transcribed and coded using the qualitative analysis programme In Vivo. Inductive and deductive coding was carried out, while drawing on framing theory to analyse the factors that influence frames. Entman's (1993) four framing sites: the communicator, audience, text and culture were analysed; while Scheufele's (1999) and deVreese's (2005) influencing factors of media frames: political and ideological orientations, routines and political and financial constraints were adapted to the ENGO context. To further triangulate the data and investigate the efficacy of the frames, nine experts were interviewed including Vietnamese journalists, media scholars and public relations practitioners. The interviews with experts were transcribed and coded using In Vivo.

\section{Literature review}

Sumrall (2009) recommended that ENGOs working in the IWT sector in Vietnam should build relationships with journalists. The interviews with key personnel revealed that ENGOs employed routines with journalists that influenced the framing of the press releases (Smith, 2017). DeLuca (2009) found in his discussions with a Greenpeace organiser that Greenpeace's communication strategies are underpinned by scholarly theories. Greenberg, Knight and Westersund (2011) found that many ENGOs in the US were employing creative agencies.

Hansen (2011) noted a dearth in journalism research on source strategies and their framing activities. There are several communication studies, however, that are relevant here. Anderson (1997) researched the campaigns of ENGOs in Britain and identified Science as an effective frame that claims makers enacted. Nisbet (2009) also found Science frames to be common in environmental campaigns. Anderson (1991) and Hansen (1993, p. 75) argued ENGOs were tied to using scientific evidence to gain legitimacy. Environmental framing scholar Lakoff (2010) argued that the truth about the environment had to be framed the right 
way to be effective because it had to resonate with audiences and cultural frames, or it would be rejected or ignored. Lakoff (2010) emphasised the importance of never repeating opposing arguments as it is impossible to negate a frame that way, something relevant to the VWP frame. Risk scholar and sociologist Ulrick Beck (1991) argued that the press could frame scientific facts in various ways to influence the public's definition of social problems and, if a cause of a risk was socially recognised, there would be pressure for change.

Collins' (2013) research into anti-logging claims makers found that it was important not to use vilifying frames in order to keep negotiations open. Lin's (2012) study of the local and international campaigns of an elephant welfare group in Thailand agreed with Collin's point, but from an Asian context. Lin found that gentle rather than critical approaches were more effective at gaining public support in Asian cultures. However, she found that negative messaging, was effective at raising awareness internationally. There was consensus among scholars of the importance of culture in framing (Entman, 1993; Anderson, 1997; Lakoff, 2010; Nisbet, 2009; Lester, 2014), while Lester (2014) argued that foreign claims makers sometimes did not understand important cultural nuances. In a finding applicable to audience frames in Vietnam, Hansen (1993) argued that Greenpeace's focus on the environmental problem and not themselves was a factor in their legitimacy.

Solesbury (1976) argued there were three main tasks for claims makers. These tasks included commanding attention, claiming legitimacy and invoking action. Benford and Snow (2000) echoed Solesbury's task of invoking action by noting the need for communications that motivate change. Key personnel that were interviewed discussed the importance of communicating issues that directly affected rhino horn users. In line with the ENGOs, Maibach, Nisbet, Baldwin, Akerlof \& Diao (2010) argued that framing issues pertinent to audiences were persuasive.

\section{Findings}

As superstitious beliefs are considered to be unscientific, the VWP frame belonged to the generic environmental framing category of Science (Nisbet, 2009; Anderson, 1991, 1997).

The frame occurred in two subthemes that were related, but clearly differentiated, which I called the Medical subtheme and the Success subtheme. It performed a causal function (Entman, 1993) blaming demand on false beliefs. The subthemes related to the two key purposes of using the horn: medical and emotional. The VWP frame appeared in the media releases of five of seven ENGOs that were analysed: ENV, Change, WildAct, WildAid and TRAFFIC and in over half of the sample overall. It did not appear in the media releases of two IENGOs in the sample: WWF and WCS.

This sentence from a WildAid press release illustrates how the Medical 
sub-theme used a metaphor framing device (Gamson \& Modigliani, 1989) to illustrate the unscientific basis of the belief:

\begin{abstract}
Belief in its purported health benefits, including treatment for cancer, fever reduction and other health problems, remains relatively high in Vietnam, despite the fact that rhino horn is composed of compressed hair and keratin, the same protein found in fingernails. (WildAid, 2015, para 2)
\end{abstract}

In its causal function as a frame, it broadly criticised the unscientific nature of traditional and recent beliefs in the medical efficacy of rhino horn by employing the fingernail framing device.

The Medical subtheme was enacted by a variety of framing devices. Framing devices included a metaphor (Gamson \& Modigliani, 1989) that the campaign has become known for, comparing rhino horn to fingernail. Other devices include words (Lakoff, 2010) or catchphrases (Gamson \& Modigliani, 1989) that challenged the belief, such as 'magic,' 'myth', 'superstition,' 'miracle cure,' 'ignorant' and 'false beliefs.'

Framing device images (Gamson \& Modigliani, 1989) included photos of rhinos photoshopped with fingers for horns, celebrities chewing their nails and bottles of fingernails, which act as fingernail metaphors (Gamson \& Modigliani, 1989) emphasising the lack of science. Framing devices enacting the Science generic frame also included selecting traditional doctors, cancer experts and hospital patients as messengers, sources, influential peers or potential interpersonal sources (Nisbet, 2009). These framing devices focused on what the buyers and users wanted, which was effective medical treatment, rather than criticising their intelligence.

In press releases, where the ENGOs focused less on what was wrong with the belief and more on what the consumers wanted, such as 'proper cancer treatment options' and how using rhino horn could 'worsen the disease and waste time and resources' (Change, 2015), the ENGOs used relevant sites (Cox, 2010) to motivate change. The medical expert sources or messengers that Change used in their press releases were Science framing devices that the ENGOs used to communicate this aspect.

The Success subtheme represented a shift away from the Medical subtheme, focusing on a wide-spread aspect of the demand, in which consumers used rhino horn to gain success (Burgess, 2016; Truong, et al., 2016). Rather than focus on a false belief, the Success sub-theme suggested an alternative to rhino horn.. TRAFFIC's Chi campaign alerted wealthy businessmen rhino horn users to the Asian cultural belief of Chi as this sentence illustrates:

The Chi campaign promotes the notion that success, masculinity and good luck flow from an individual's internal strength of character and refutes 
the view that these traits come from a piece of horn. (TRAFFIC, 2014, September 22).

It expressed a positive view of Vietnamese culture, providing a solution, rather than a critical view as the Medical subtheme did with the fingernail metaphor. Framing devices included words and catchphrases such as 'chi', 'success', 'status', 'masculinity', 'prosperity' and 'good luck'. Images featured photographs of expensive cars with successful businessmen. The use of sources including celebrities, business leaders, and government officials also enacted the 'Success' subtheme.

ENV, however, was quite critical of users and their beliefs in the Success sub-theme as these exerts from a press release illustrates: ' ... by letting consumers know how foolish they are for thinking that the use of rhino horn makes them special in any way' and 'If consumers look in the mirror they may see an important person but if they look at their hands they will see the blood of rhinos' (ENV, 2014).

\section{Cultural and other factors of influence and efficacy}

This section will discuss the cultural and other factors that influenced the production of the VWP frame (Table 2).

Interviews with key personnel showed the Medical subtheme of the VWP frame was possibly influenced by frames that were held by the communicators, or ENGO ideologies. A number of ENGO personnel said they thought the belief in rhino horns medical efficacy was false or 'a complete fallacy' (Representative B, personal communication, November 17, 2016), while others, as animal-lovers, actually 'hate' (T. Tran, personal communication, July 2, 2016) users, because they saw them as harming animals. John Baker, WildAid's managing director, said WildAid's 'Nail Biter' campaign was designed in conjunction with creative agencies to attract attention with humour. He said the campaign aimed to make rhino horn users 'look dumb' by portraying them as fingernail biters ( $\mathrm{J}$ Baker, personal communication, November 17, 2016). These communicator ideological factors may help explain why ENGOs compared a highly regarded medicine in TM to chewing fingernails.

The comments of one source suggested that the fingernail framing device was originally conceived to be a fun scientific message targeting international audiences, before it was applied in Vietnam:

... if we talk about saving rhino in far off lands, the average consumer in America or the UK or whatever, they're like, 'Oh that's nice and I hate to see them die, but what can I do and how does that relate to me.' So you always look to make the connection, so by talking to the people about their fingernails you can certainly have an impact. (Representative B, personal communication, November 17, 2016) 


\begin{tabular}{|c|c|}
\hline Categories of influencing factors & Influencing factors revealed in interviews \\
\hline $\begin{array}{l}\text { ENGO political and ideological } \\
\text { orientations and communicator } \\
\text { frames }\end{array}$ & $\begin{array}{l}\text { - ENGOs believed the TM use was a fallacy. } \\
\text { - ENGOs were animal lovers. } \\
\text { - ENGOs disliked users. } \\
\text { - ENGOs believed the fingernail device was } \\
\text { funny. } \\
\text { - ENGOs recognised and respected the medicinal } \\
\text { use of rhino horn in the traditional way. }\end{array}$ \\
\hline ENGO routines & $\begin{array}{l}\text { - ENGOs responded to feedback from public } \\
\text { and government. } \\
\text { - ENGOs employed local staff. } \\
\text { - ENGOs sought feedback from friends and } \\
\text { family. } \\
\text { - ENGOs sought feedback from journalists. } \\
\text { - ENGOs copied and pasted background infor- } \\
\text { mation from previous press releases. } \\
\text { - International ENGOs worked with local ENGOs } \\
\text { on messages. } \\
\text { - ENGOs looked for catchy messages and im- } \\
\text { ages. } \\
\text { - ENGOs used expert messengers. } \\
\text { - ENGOs used messengers with cultural and } \\
\text { socio-economic proximity to their target } \\
\text { audience. } \\
\text { - ENGOs translated and simplified scientific } \\
\text { papers for the public. } \\
\text { - ENGOs were informed by scholarly research. }\end{array}$ \\
\hline $\begin{array}{l}\text { ENGO political and financial } \\
\text { constraints }\end{array}$ & $\begin{array}{l}\text { - ENGOs with funding commissioned research } \\
\text { organisations. } \\
\text { - ENGOs with funding commissioned creative } \\
\text { agencies. }\end{array}$ \\
\hline
\end{tabular}

Several personnel said the critical aspects of the Medical sub-theme, such as the fingernail framing device, were met with distrust and anger by the Vietnamese government and public, because it was not seen as true, or as an over-simplification of the science. Hence audience frames came into play:

But even with the message of the fingernail, we got a lot of complaints from the government officer and other public member. That's why we stopped using that message. When the conservation organisation says that rhino horn is the same, like fingernail, it's not true at all. (D. Nguyen, personal communication, November 18, 2016). 
Representative A suggested that simplifying the science was an ENGO routine that was problematic: "A lot of the time we are sending out messages that are too simplified' (Representative A, personal communication, November 18, 2016). Feedback, from the public and the government, through employing local staff and seeking feedback from family and friends, was an important influencing factor, particularly in respect to the culture:

...you always need to have the local people to check to see it fits with the cultures... Of course the first is the office. We are the local people. We understand the messages and then our friends and families and if they are all opposed to it, other audience who do not understand the problem they will be opposed to it as well... (V.H. Duong, personal communication, November 18, 2016)

Two ENGOs, Change and TRAFFIC, debranded their campaigns, as personnel said the Vietnamese public would dismiss messages that came from a 'conservation voice' (T. Nguyen, personal communication, November 17, 2016). WCS Policy Director Duong Viet Hong said WCS did not try to refute rhino horns' medical credentials on the basis of it being made from keratin, as rhino horn has been shown to have medical benefits for a long time:

We do not say that because some people are really angry. Of course, it has fingernail, it has keratin but it has other substance that you don't... That's why it's been used in Traditional Medicine for a long, long time and according to the research we've seen it does have the effect of reducing fever. (V.H. Duong, personal communication, November 18, 2016).

Interviews with journalists revealed some of them shared Duong Viet Hong's views that ENGOs' fingernail claims had no scientific basis, while other media representatives said the fingernail claims were widely reported, because they were effective at illustrating that the belief is false. ENGOs in Vietnam sought the feedback of journalists following Sumrall's (2009) research. A range of the media relations routines had potential to influence frames.

In addition to the long list of journalists on their contact list, ENV cultivated a 'top ten list' of journalists for whom they organised 'media café chats' (D Nguyen, personal communication, November 18,2016). These are casual events rather than press conferences. 'It's kind of like an informal café discussion', where journalists and ENGO personnel can 'talk freely' (D. Nguyen, personal communication, November 18, 2016). They talked about important stories in more detail and tried to explain the ENGO's position, when journalists did not understand. Sometimes they tried to encourage journalists to investigate an important issue more deeply. At the media café chats the journalists often provided 
feedback about the ENGOs press releases, 'about our approach, about the media statement, whether it's interesting or not' (D. Nguyen, personal communication, November 18, 2016). Often the journalists complained the ENGO included too many messages, making the press releases too long. ENV Vice-Director Nguyen Thi Phuong Dung explained that ENV tended to include too many messages in their press releases because they were targeting diverse audiences.

Change Director Hoang Thi Minh Hong described a similar tactic employing casual media briefings rather than press conferences. Another ENGO worked collaboratively with journalists via e-mail to edit press releases:

I do take advice from the journalist about fixing or changing the media release, because they work with the public more than I do... So we draw up a media release form and if they don't understand it they send it back. And if there's something they want to fix, they want to add more, something they want to remove, they send it back... So we work with them together to make sure we get the draft and when we get the final draft, we send. (Representative A, personal communication, November 17, 2016)

Duong Viet Hong explained that WCS provided Vietnamese journalists with a broad range of relevant information that was not related to WCS, to keep them generally informed about important issues regarding wildlife trafficking. She said WCS held media training workshops, where they fed journalists stories and explained how journalists could avoid inadvertently promoting demand:

And we also present some of the do and don'ts while writing about wildlife trafficking because some of the journalists might unintentionally promote the wildlife trade in their writing and we don't want that (V.H. Duong, personal communication, November 18, 2016)

Duong Viet Hong said WCS messaging focused only on the spurious medical claims and who was to blame for spreading them:

Then we can give them a message of how the research has been done on the features of rhino horn to say that it doesn't have all those advertised benefits people are talking about right now. And those benefits don't have any basis. And it's often created by the wildlife traders and each year there's more new benefits and that's the proof that it's not traditional. It doesn't have any basis. (V.H. Duong, personal communication, November 18, 2016)

This suggests that the frame could be adjusted to be more accurate, as Lakoff (2010) argued, to better connect with audiences. It could be argued that such frame adjustments could be done via Entman's four functions of the frame (1993), in this case by adjusting the causal/blame function.

The fingernail framing device, despite several ENGOs' decision not to use it, 
still persisted in press releases in a competing frame. A possible explanation was an ENGO routine of copy and pasting background paragraphs, which could be remedied by making personnel more frame-aware and breaking the routine. To additionally reduce the journalists' routine of copying and pasting the fingernail device into stories noted by Journalist A (personal communication, November 22, 2016), ENGOs could utilise their unique relationships with journalists.

Partnerships between IENGOs and local ENGOs, and the relationship between IENGOs' head office and their Vietnamese office were also influencing factors. WildAid's director John Baker described a routine with their local partner Change: '.. we work together on crafting the press releases, I often start with their drafts and we craft them together' (J. Baker, personal communication, November 18, 2016).

\section{Theoretical discussion}

The Medical subtheme was widely used by ENGOs and in the media, as it was an effective framing device for raising awareness (Newspaper Editor A, 2016, personal communication, November 22, 2016), fulfilling an important function of claims makers (Solesbury, 1976). However, the subtheme apparently angered some members of the Vietnamese public and the government because it was culturally insensitive. Collins (2013) argued that frames should avoid being vilifying to keep negotiations open, while Lin (2012) observed that in cross cultural communication with Asian cultures a gentle approach was needed.

Some interviews with ENGOs showed the ENGO personnel had strong negative feelings about both belief in rhino horn's efficacy (Baker, personal communication, November 18, 2016; Representative B, 2016, personal communication, November 17, 2016) and the consumers themselves (T. Tran, personal communication, July 2, 2016; D. Nguyen, 2016, personal communication, November $18,2016)$. This suggests an underlying motivation in the communicator's frames and ideologies that influenced the Medical subtheme to make them critical or insulting of users and their beliefs.

The interviews also suggested that ENGOs were thinking of international audiences when they designed fingernail messages. (Representative B, personal communication, 17 November 17, 2016) because the fingernail metaphor was easily relatable and humorous. Lin (2012) found with an elephant ENGO in Thailand that while local messages should be gentle, critical international messages were successful at raising awareness and building support overseas. This dual approach, however, appeared to be problematic in Vietnam because Vietnamese journalists consume the international news media where they would come across critical messages. Critical messages were perpetuated because foreign claims makers did not understand important cultural nuances (Lester, 2014).

The ENGOs received feedback from the public and the government that the 
fingernail framing device was culturally insensitive, through an ENGO routine of employing local staff and seeking feedback from friends and family. Hence several ENGOs rejected the fingernail device. Instead of using the fingernail and myth devices, some ENGOs used medical sources who recommended modern cancer cures. Thus, ENGOs switched from a causal function of the frame, where the cause of the problem was a false belief, to a more culturally sensitive treatment function (Entman, 1993). This approach performed an important motivating task (Benford \& Snow, 2000) by using issues pertinent to the audience (Maibach et al., 2010) and contemporary medical opinion.

By suggesting that ENGOs should blame new spurious medical claims and the illegal traders that spread them, Duong Viet Hong of WCS was referring to fine tuning the causal/blame function of the frame to avoid criticising the audience frame, a deep-seated belief in rhino horn's lofty place in TM.

ENGOs received feedback from journalists via a variety of unusual media relations activities discussed in the findings. Some journalists said the fingernail claims lacked scientific evidence, echoing Hansen (1993) and Anderson's (1991) view that ENGOs rely on science for legitimacy, while other journalists said they had used the device as it was an effective way of communicating the lack of science (Newspaper Editor A, personal communication, November 22, 2016) suggesting that the metaphor was a powerful framing device (Gamson \& Modigliani, 1989).

Research activities that TRAFFIC undertook were a key influencing factor in the production of the Success subtheme, reflecting their financial capacity. The approach was much more audience focused than the Medical subtheme. Research activities included engagement with scholarly research in related disciplines, social marketing research and online communities of practice. In line with other IENGOs and TRAFFIC's previous campaigns, TRAFFIC employed a creative agency for its Chi campaign.

\section{Conclusion}

ENGOs have extensively employed a science frame that questions the science behind rhino horn's medical effectiveness to discourage strong consumer demand in Vietnam. By employing the science frame, ENGOs questioned the medical and health benefits of this long standing and highly regarded traditional medicine in Vietnam by comparing the medical or health effect of taking rhino horn to chewing fingernails. The ENGO media outputs often called the belief or the science behind its medical efficacy a myth or a false belief in a magical medicine.

ENGOs employed two subthemes of the VwP frame in their media outputs: the Medical subtheme, which questioned the medicinal qualities of rhino horn, and the Success subtheme, which questioned the use of rhino horn as a status 
symbol and as a magical potion to achieve success. Both subthemes are underpinned by a belief in Vietnam that rhino horn is extremely valuable and rare as a traditional medicine.

The findings suggested that when ENGOs used the fingernail and myth framing devices in the VWP frame it was problematic. Feedback from the Vietnamese public and government suggested the devices were untrue and disrespectful of Vietnamese culture. However, the devices were effective at commanding public and media attention, possibly because of the powerful framing effect of the metaphor. More focus was needed in respect of audience and cultural frames rather than communicator frames. Hence ENGOs tried to be more accurate in communicating what beliefs were the culprits and who was to blame for them. Instead of negating audience frames, ENGOs employed more science and medical experts that suggested alternative ways for the public to achieve what they want. This helped to gain legitimacy, which emerged as a chief concern, illustrated by de-branding media outputs in line with Greenpeace's practice (Hansen, 1993), and to avoid vilifying traditional beliefs.

A key finding was in the way ENGOs routinely accessed local feedback from friends, family and local staff, that helped them to be culturally sensitive. Feedback from journalists was sought, as Sumrall (2009) had recommended. Local ENGO personnel had developed strong relationships with local journalists, through activities such as media café chats and co-editing of press releases. The two-way communication model benefited both sides by enhancing better understanding of the illegal demand for rhino horn for journalists and better understanding what was interesting to journalists and the public for the ENGOs. The media provided a mix of feedback on the Medical subtheme of the VWP frame, so ENGOs appeared to give the frame less prominence, but continued to include it as a competing frame. The mixed feedback included that the fingernail message was effective at raising awareness, but it wasn't scientifically supported or culturally appropriate.

The factors that influenced the Success subtheme appeared to be less organic, with more focus on an evidence-based approach than the way in which the Medical subtheme evolved. The use of creative agencies in Vietnam shows that the practice of ENGOs in the US and Canada employing creative agencies (Greenberg et al. 2011) is also employed in Vietnam. The importance that TRAFFIC placed on scholarly research of multiple disciplines to find solutions to reduce demand echoes DeLuca's (2009) findings with Greenpeace. Implications for further research may be the influence of international donors on ENGO campaigns in IWT, the influence of creative agencies on framing in IWT and the use of the VWP frame in media stories about the medical use of other animal parts such as tiger penises in Asia.

The research revealed the use of journalism framing theory as an effective 
theoretical framework to analyse and evaluate the communication strategies of ENGOs in cross cultural contexts. Overall the ENGOs' media outputs suggest their campaigns are taking a positive direction. As Lakoff (2010) argued, reframing environmental issues to overcome entrenched conservative values takes time.

\section{References}

Anderson, A., (1991). Source strategies and the communication of environmental affairs. Media, Culture and Society, 13(4), 459-476.

Anderson, A., (1997). Media, culture and the environment. London: UCL Press.

Benford, R.D. \& Snow, D.A. (2000). Framing processes and social movements: An overview and assessment', Annual Review of Sociology, 26 (1), 611-639.

Blood, R. W., Putnis, P., \& Pirkis, J. (2002). Mental-illness news as violence: a news frame analysis of the reporting and portrayal of mental health and illness in Australian media. Australian Journal of Communication, 29(2), 59.

Burgess, G. (2016). Powers of persuasion? TRAFFIC Bulletin, 28(2), 65.

Cappella, J.N., and Jamieson, K.H., (1997). Spiral of cynicism: The press and the public good. Oxford, UK: Oxford University Press.

Change, (2015, August 20). Understanding cancer workshop — experts dispelling misconceptions about cancer treatment. [Translated from Vietnamese].

Cooper, C., (2006). 'This is our way in': The civil society of environmental NGOs, South-West China Government and Opposition, 41(1), 109-136.

Cox, R. (2010). Beyond frames: Recovering the strategic in climate communication', Environmental Communication: A Journal of Nature and Culture, 4(1), 122-133.

DeLuca, K. M. (2009). Greenpeace international media analyst reflects on communicating climate change. Environmental Communication, 3(2), 263-269.

deVreese, C.H., (2005). News framing: Theory and typology, Information design journal + document design, 13(1), 51-62.

Drury, R., (2009). Hungry for success: Urban consumer demand for wild animal products in Vietnam, Conservation and Society, 9(3), 247-257.

Education for Nature Vietnam (2014, September 18). Vietnamese delegation arrives in South Africa on mission to help protect rhinos. Retrieved from https://www.envietnam.org/

Emslie, R., (2012a). Ceratotherium simum, The IUCN red list of threatened species 2012. Retrieved from http://dx.doi.org/10.2305/IUCN.UK.2012.RLTS.T4185A16980466.en

Emslie, R., (2012b).Diceros bicornis, The IUCN Red List of Threatened Species 2012. Retrieved 24 February 2018 from http://dx.doi.org/10.2305/IUCN.UK.2012.RLTS. T6557A16980917.en

Entman, R.M., (1993). Framing: Toward clarification of a fractured paradigm, Journal of communication, 43(4), 51-58.

Gamson, W.A. \& Modigliani, A., (1989). Media discourse and public opinion on nuclear power: A constructionist approach. American Journal of Sociology, 95(1), 1-37.

Given, L.M. (Ed), (2008). The Sage encyclopedia of qualitative research methods. Thousand Oaks, CA: SAGE Publications.

Gitlin, T., (1980). The whole world is watching: mass media in the making and unmaking of the New Left, Berkeley, CA: University of California Press.

Greenberg, J., Knight, G. \& Westersund, E. (2011) Spinning climate change: Corporate 
and NGO public relations strategies in Canada and the United States. International Communication Gazette, 73(1-2), 65-82.

Hansen, A., (1993). Greenpeace and the press coverage of environmental issues. In Hansen, A., (Ed.) The Mass Media and Environmental Issues (pp. 150-178). Leicester, UK: Leicester University Press.

Hansen, A., (2011). Communication, media and environment: Towards reconnecting research on the production, content and social implications of environmental communication. International Communication Gazette, 73(1-2), pp. 7-25.

Lakoff, G., (2010). Why it matters how we frame the environment. Environmental Communication, 4(1), 70-81.

Lester, L., (2014). Transnational publics and environmental conflict in the Asian century. Media International Australia, 150(1), 167-178.

Lin, T.T., 2012. 'Cross-platform framing and cross-cultural adaptation: Examining elephant conservation in Thailand', Environmental Communication: A Journal of Nature and Culture, 6(2), pp. 193-211.

Lowe, P. and Goyder, J., (1983). Environmental groups in politics. London, UK: George Allen and Unwin.

Milliken, T., \& Shaw, J., (2012). The South Africa-Viet Nam rhino horn trade nexus: A deadly combination of institutional lapses, corrupt wildlife industry professionals and Asian crime syndicates. Retrieved from http://www.trafficj.org/publication/12 The_SouthAfrica-VietNam_RhinoHorn_Trade_Nexus.pdf

Milliken, T. (2014). Illegal trā̄e in ivory and rhino horn: an assessment to improve law enforcement under the wildlife TRAPS project. USAID. Retrieved August 2, 2018 from https://www.usaid.gov/sites/default/files/documents/1865/W-TRAPS-ElephantRhino-report.pdf

Maibach, E. W., Nisbet, M., Baldwin, P., Akerlof, K., \& Diao, G. (2010). Reframing climate change as a public health issue: an exploratory study of public reactions. BMC Public Health, 10(1), 299.

Mol, A.P., (2009). Environmental governance through information: China and Vietnam. Singapore Journal of Tropical Geography, 30(1), 114-129.

Nisbet, M.C., (2009). Communicating climate change: Why frames matter for public engagement. Environment: Science and Policy for Sustainable Development, 51(2), 12-23.

Rademeyer, J., (2012). Killing for profit: Exposing the illegal rhino horn trade. Cape Town, SA: Zebra Press.

Scheufele, D.A., (1999). Framing as a theory of media effects. Journal of Communication, 49(1), 103-122.

Smith, M., (2008), The growing NGO lobby. Thanh Nien. Retrieved August 13, 2017 from http://www.thanhniennews.com

Smith, M.S. (2017). The framing of rhino horn demand reduction by Vietnamese ENGOs: cultural and other factors influencing the 'responsibility'frame in ENGO media outputs. Unpublished master's thesis, Griffith University, Queensland, Australia.

Solesbury, W., (1976). The environmental agenda. Public Administration, 54(4), 379-397.

Sumrall, K.A., (2009). Confronting illegal wildlife trade in Vietnam: the experience of Education for Nature-Vietnam. Unpublished doctoral dissertation, University of Michigan, Ann Arbor, USA.

Tankard, J.W., (2001). The empirical approach to the study of media framing. In Reese, S., Gandy, O. and Grant, A., (Eds.) Framing public life: Perspectives on media and our understanding of the social world, (pp. 95-106). London, UK: Routledge. 
Traffic. (2014, September 22). Innovative campaign promotes success from within.

Truong, V.D., Dang, N.V.H.,\& Hall, C.M., (2016). The marketplace management of illegal elixirs: illicit consumption of rhino horn. Consumption Markets \& Culture, 19(4), 353-369.

WildAid. (2015, January 22). Record number of rhinos killed in South Africa last year. Retrieved from https://wildaid.org

Yang, G., \& Calhoun, C., (2013). Media, civil society and the rise of the green public sphere in China. In Lester, L. and Hutchins, B., (Eds.) Environmental conflict and the media, New York, NY: Peter Lang Publishing.

Michael Smith completed a Master of Arts Research at Griffith University in 2017. As a freelance environmental journalist, he has covered the illegal trade in rhino horn since Vietnam's last rhino was killed for its horn in 2010.

Micsmith66@gmail.com
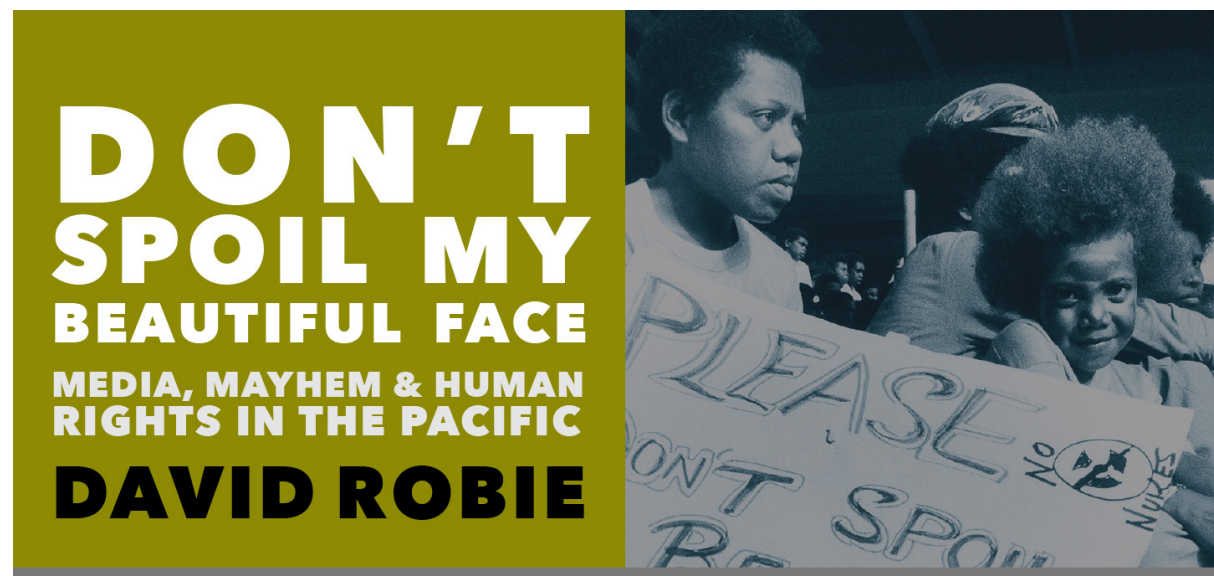

"This is an extraordinary 'secret history' of a vast region of the world of which David Robie has been a rare expert witness. What makes this epic work so timely is that it allows us to understand the Asia-Pacific at a time of renewed cold war ambitions and dangers." - John Pilger

little island press • ISBN 978-1-877484-25-4 • www.littleisland.co.nz 